\title{
Coastal sea level rise in southern Europe and the nonclimate contribution of vertical land motion
}

\author{
G. Wöppelmann ${ }^{1}$ and M. Marcos ${ }^{2}$ \\ Received 27 July 2011; revised 3 November 2011; accepted 4 November 2011; published 10 January 2012.
}

[1] In this study, we extend the advanced approach of combining tide gauge and satellite altimetry data with supplemental equations from adjacent tide gauge records of at least 30 years of common data to investigate the relative importance of the nonclimate contribution of vertical land movement to the observed rates of sea level change along the coasts of southern Europe. The sensitivity tests proved that the advanced approach is robust and accurate at the submillimeter per year level of around $0.4 \mathrm{~mm} \mathrm{yr}^{-1}$ in estimating rates of vertical land movements. It enabled identifying stations displaying large rates of vertical land movements that must be taken into account when predicting future sea level rise and appraising the exposure to its impacts on populations and assets. The average rate of coastal climate-related sea level rise in the Mediterranean Sea was consequently revisited to be of $1.7 \mathrm{~mm} \mathrm{yr}^{-1}$ over the past century, whereas the Atlantic northern Iberian coast revealed a significant high rate of sea level rise in excess of $3.4 \mathrm{~mm}$ $\mathrm{yr}^{-1}$ for the past 70 years. Future work should consider applying this powerful approach to other geographic contexts as a useful source of supplementary data for geodynamic studies.

Citation: Wöppelmann, G., and M. Marcos (2012), Coastal sea level rise in southern Europe and the nonclimate contribution of vertical land motion, J. Geophys. Res., 117, C01007, doi:10.1029/2011JC007469.

\section{Introduction}

[2] Tide gauges measure the sea level height with respect to the land upon which the tide gauge benchmarks are grounded. Whereas this observational information may appear as the most adequate and useful quantity for coastal management, to devise any sustainable development plan of the coastline it is desirable to understand what are the causes underlying the observed relative sea level rise and what are the respective magnitudes of these causes. In particular, a major question concerns the relative contributions to sea level rise due to climate change (ocean thermal expansion and/or melting of land-based ice) and due to local land subsidence at the coast. To identify the causes of the changes acting at a particular place on the interdecadal to centennial timescales and to assess their relative importance, monitoring the vertical land movement at tide gauges has become an essential and vital aspect of in situ sea level observing systems [Merrifield et al., 2010].

[3] Much research over the past 10 years has focused on vertical land movement determination at tide gauges using the GPS in continuous operating mode [Blewitt et al., 2010]. Worthwhile results have been obtained on the global scale, showing reduced dispersion of individual and regional GPScorrected rates of sea level change [Wöppelmann et al., 2007], provided a global state of the art reanalysis strategy of the GPS observations is applied using the same models,

\footnotetext{
${ }^{1}$ LIENSS, Université de la Rochelle-CNRS, La Rochelle, France. ${ }^{2}$ IMEDEA, CSIC-UIB, Esporles, Spain.
}

Copyright 2012 by the American Geophysical Union. 0148-0227/12/2011JC007469 corrections, and parameterizations over the complete GPS data span. However, although considerable efforts are undertaken worldwide to upgrade tide gauge networks with colocated permanent GPS stations, their numbers are still limited [Merrifield et al., 2010]. In addition, the geodetic connection between the GPS antenna and the nearby tide gauge benchmark is often missing, which raises the issue of assuming that the vertical land movement sensed by the GPS antenna corresponds to the actual land movement affecting the tide gauge record when the GPS antenna is distant [e.g., Bevis et al., 2002]. It is worth reminding here that to be useful for long-term sea level applications, site displacements at tide gauges should be determined with greater accuracy than the sought-after signal of 1 to $3 \mathrm{~mm} \mathrm{yr}^{-1}$ rate of climate-related sea level change over multidecadal to century timescales [Church et al., 2010], consequently requiring local stability between the GPS antenna and the tide gauge benchmark at the submillimeter per year level or accurate monitoring through repeated precise leveling surveys.

[4] An alternative approach to accurately estimate vertical land movements was devised by Kuo et al. [2004] from the combination of satellite and in situ sea level data. The advanced approach of Kuo et al. is a refined method adapted from the classical approach of subtracting tide gauge data relative to the coast from geocentric satellite altimetry data [e.g., Cazenave et al., 1999] that include constraint equations from long tide gauge records. Although the advanced approach showed excellent results of similar performance to state of the art vertical GPS velocities in terms of precision and accuracy [Kuo et al., 2004, 2008], it is interesting to note that few studies have implemented the ingenious algorithm of Kuo et al. [2004] that takes advantage of the full 
range of long tide gauge records. As far as our review could reach, the classical approach, which is limited to the satellite altimetry data span, has prevailed in use [e.g., Garcia et al., 2007; Ray et al., 2010; Trisirisatayawong et al., 2011]. Thus, questions arose whether the extension of the advanced approach is valid in different oceanic contexts. For instance, to what extent the underlying assumptions are valid for the method to be applied in the semienclosed sea of the Mediterranean Sea or in the Atlantic Iberian coast, as a tentative exercise toward open oceanic conditions.

[5] In this study, we base on the Kuo et al. [2004] approach that overcomes the current GPS limitations of data availability at tide gauges to estimate vertical land movements. The approach was applied at tide gauges along the coasts of southern Europe displaying records longer than 40 years and contemporary to satellite altimetry data for at least 8 years. The results permitted to bring out the climate-change-driven sea level rise along these coasts. They demonstrated the performance of the advanced Kuo et al. approach in new geographic and oceanic contexts. It further allowed identifying particular areas where subsidence was accurately assessed that could exacerbate the predicted climate-induced sea level rise if they continue at the present estimated rate of change.

\section{Data Sets}

\subsection{Satellite Altimetry Data}

[6] Gridded monthly global sea level anomalies with a map spacing of $1 / 4^{\circ} \times 1 / 4^{\circ}$ were obtained from the satellite multimission product of the Archiving, Validation, and Interpretation of Satellite Oceanographic (AVISO) data server (http:// www.aviso.oceanobs.com, accessed May 2011). This data set was produced by combining data from several satellite altimetry missions and spans the period from October 1992 to present. All the state-of-the-art geophysical corrections were applied in this data set. In particular, the atmospheric correction using the so-called dynamic atmospheric correction (DAC) was applied too [Volkov et al., 2007], combining the standard inverted barometer correction and outputs from MOG2D barotropic model [Carrère and Lyard, 2003], which improves the representation of high-frequency (greater than $1 / 20$ cycles per day) atmospheric forcing as it takes into account both pressure and wind effects. However, in this study the atmospheric correction was added back to the altimetry data set in order to make it comparable to the tide gauge observations. An alternative approach would be to correct the tide gauge observations for the atmospheric effects and compare with the corrected altimetry data. However, no differences would be expected if the corrections applied are consistent (same model).

\subsection{In Situ Sea Level Data}

[7] Time series of monthly averages from the "revised local reference (RLR)" tide gauge data set of the Permanent Service for Mean Sea Level (PSMSL; http://www.pol.ac.uk/ psmsl) were used where available along the coasts of the Iberian Peninsula and Mediterranean Sea. The RLR is the most appropriate tide gauge data set for long-term trend sea level studies as its records were previously checked and corrected for local datum continuity over time relative to benchmarks on the vicinity [Woodworth and Player, 2003].
This data set was supplemented with the tide gauge record from Alexandria, Egypt, which proved to show a worthwhile time series [Frihy, 2003] and was kindly provided by Prof. Frihy updated up to 2005. We also extended the PSMSL record of Cascais, Portugal, with 20 years of data (1985 to 2005) kindly provided by Instituto Geografico Português and already quality checked by Marcos and Tsimplis [2008].

[8] In this study, the focus was set on tide gauges of at least 40 years long time series in order to precisely determine rates of relative sea level change, assuming that the impact of the low-frequency decadal signals was negligible then, and the resulting rates represented the long-term climate contributions plus the uncorrected vertical movement of the land on which the tide gauges are grounded. Tide gauge records longer than 40 years typically display standard errors in linear trends of less than $0.5 \mathrm{~mm} \mathrm{yr}^{-1}$ [Douglas, 2001]. This is particularly confirmed in the Mediterranean Sea [e.g., Tsimplis and Spencer, 1997]. Tide gauge records were rejected if they did not contain more than $80 \%$ of valid data within the time span of at least 40 years. Tide gauge stations fulfilling these requirements are listed in Table 1.

[9] The tide gauge stations located around the Strait of Gibraltar, namely Cadiz, Algeciras, Tarifa, Malaga and Ceuta, were finally not considered in the analysis. Indeed, Marcos and Tsimplis [2008] reported a large scatter of sea level trends in this region that prevented from identifying a common regional sea level trend. In addition, further analysis and comparisons among nearby shorter records revealed that all these stations display an anomalous behavior in terms of rate of sea level change. For example, when Cadiz is compared with nearby Atlantic stations (Huelva and Bonanza), the differences in short-term trends (up to 9 years) are between 10 and $20 \mathrm{~mm} \mathrm{yr}^{-1}$. The same applies to Malaga where, in spite of using longer periods, differences show up to $8 \mathrm{~mm} \mathrm{yr}^{-1}$. Details about these stations and the quality of their records are given by Marcos and Tsimplis [2008].

[10] In the Aegean Sea, Khalkis North was also discarded from the analysis because it displayed a poor correlation with neighboring stations (not shown here). Note that this station is located at the Euripus Strait where strong tidal currents have been observed [Tsimplis, 1997]. In addition, its record has shown a clear change in its variance during the 1970s. Moreover, in the Aegean Sea, Levkas was removed after a close examination of its record in which two large jumps were found around 1979-1980 and 2003. These two Greek series were considered questionable by Marcos and Tsimplis [2008], together with most tide gauge records in the Aegean Sea. Actually, among our selected records, only Thessaloniki was labeled as a good quality time series in this previous study. The rest showed a large dispersion in trends and correlations that led Marcos and Tsimplis [2008] to suggest that repeated problems with long-term benchmark continuity could be affecting the Greek tide gauges. Although caution was advisable based on the above-mentioned results, Katakolon, Alexandroupolis, and Leros data were included in the present study based on our own examination of the updated time series whose individual behavior were apparently correct.

[11] Because of the short overlapping time span with the satellite altimetry period of only 5 years, Genoa was finally removed from the analysis, despite its length and good quality. Indeed, because linear trends of differences between tide gauge records and satellite altimetry data were to be 
Table 1. Contemporary Tide Gauge Records in Southern Europe Longer Than 40 Years With at Least $80 \%$ of Valid Data

\begin{tabular}{|c|c|c|c|c|c|c|}
\hline Station & PSMSL & Latitude & Longitude & Time Span & Length (Years) & Gaps (\%) \\
\hline Santander I & 485 & 43.467 & -3.800 & 1943-2009 & 66.67 & 2.8 \\
\hline La Coruña I & 484 & 43.367 & -8.400 & 1943-2009 & 66.83 & 2.4 \\
\hline Vigo & 483 & 42.233 & -8.733 & 1943-2009 & 66.83 & 0.9 \\
\hline Cascais $^{\mathrm{a}}$ & 52 & 38.683 & -9.417 & $1882-2005$ & 124.00 & 7.0 \\
\hline Cadiz III $^{\mathrm{a}}$ & 985 & 36.533 & -6.283 & 1961-2009 & 49.00 & 3.1 \\
\hline Algeciras $^{\mathrm{a}}$ & 490 & 36.117 & -5.433 & $1943-2002$ & 60.00 & 18.9 \\
\hline Tarifa $^{a}$ & 488 & 36.000 & -5.600 & 1943-2009 & 66.33 & 6.3 \\
\hline Malaga $^{a}$ & 496 & 36.717 & -4.417 & 1944-2009 & 66.00 & 18.1 \\
\hline Ceuta $^{\mathrm{a}}$ & 498 & 35.900 & -5.317 & 1944-2009 & 65.83 & 3.5 \\
\hline Marseille & 61 & 43.300 & 5.350 & 1885-2009 & 124.92 & 2.6 \\
\hline Genoa $^{a}$ & 59 & 44.400 & 8.900 & 1884-1997 & 114.00 & 21.7 \\
\hline Venezia (PDS) & 168 & 45.433 & 12.333 & 1909-2000 & 92.00 & 5.9 \\
\hline Trieste & 154 & 45.647 & 13.759 & $1905-2010$ & 106.00 & 5.7 \\
\hline Rovinj & 761 & 45.083 & 13.629 & 1955-2008 & 53.58 & 0.5 \\
\hline Bakar & 353 & 45.300 & 14.533 & $1930-2008$ & 79.00 & 13.9 \\
\hline Split Marjana & 685 & 43.508 & 16.392 & $1952-2008$ & 56.67 & 0.6 \\
\hline Split G. Luka & 352 & 43.507 & 16.442 & 1954-2008 & 54.83 & 0.0 \\
\hline Dubrovnik & 760 & 42.658 & 18.063 & $1956-2008$ & 53.00 & 0.8 \\
\hline Levkas $^{\mathrm{a}}$ & 1239 & 38.833 & 20.700 & 1969-2010 & 41.83 & 15.9 \\
\hline Katakolon & 1240 & 37.633 & 21.318 & $1969-2010$ & 42.00 & 11.3 \\
\hline Khalkis North $^{\mathrm{a}}$ & 1237 & 38.467 & 23.600 & 1969-2010 & 42.00 & 12.5 \\
\hline Thessaloniki & 373 & 40.617 & 23.033 & 1969-2010 & 41.83 & 10.0 \\
\hline Alexandroupolis & 1238 & 40.850 & 25.883 & 1969-2010 & 42.00 & 12.1 \\
\hline Leros & 1233 & 37.083 & 26.883 & 1969-2010 & 41.75 & 20.4 \\
\hline Alexandria & 503 & 31.217 & 29.917 & 1944-2006 & 62.67 & 4.8 \\
\hline
\end{tabular}

${ }^{\mathrm{a}}$ Station was discarded for the reasons explained in the text.

computed, we focused on time series with an overlapping period with altimetry data of at least 8 years (section 4 ). The tide gauge stations selected in this study are shown in Figure 1, whereas Figure 2 highlights their period of operation.

[12] The latest data used were from December 2010. The record with the longest time span extended back to 1885 at Marseille, France [Letetrel et al., 2010]. The selected stations are mostly the representatives of the Atlantic Iberian coast and the northern coast of the Mediterranean basin, except Alexandria, which is located in the southern shores. While only one station is left in the western Mediterranean (Marseille), the Adriatic Sea, in contrast, is very well represented by long and good quality records (from Venezia to Dubrovnik), as was already pointed out in previous work [e.g., Tsimplis and Spencer, 1997; Marcos and Tsimplis, 2008]. One Greek station is located in the Ionian Sea, while three of them are in the Aegean Sea.

\section{Estimation of Vertical Land Movements}

\subsection{Combining Tide Gauge and Satellite Altimetry Data}

[13] The approach implemented here to estimate vertical land movements at tide gauge sites with the highest possible accuracy is based on Kuo et al. [2004] methodology. This approach has been successfully applied to Fennoscandia, the Great Lakes and Alaska [Kuo et al., 2004, 2008]. It is an advanced method adapted from the basic classical approach of subtracting tide gauge data relative to the coast from geocentric satellite altimetry data [e.g., Cazenave et al., 1999]. In this

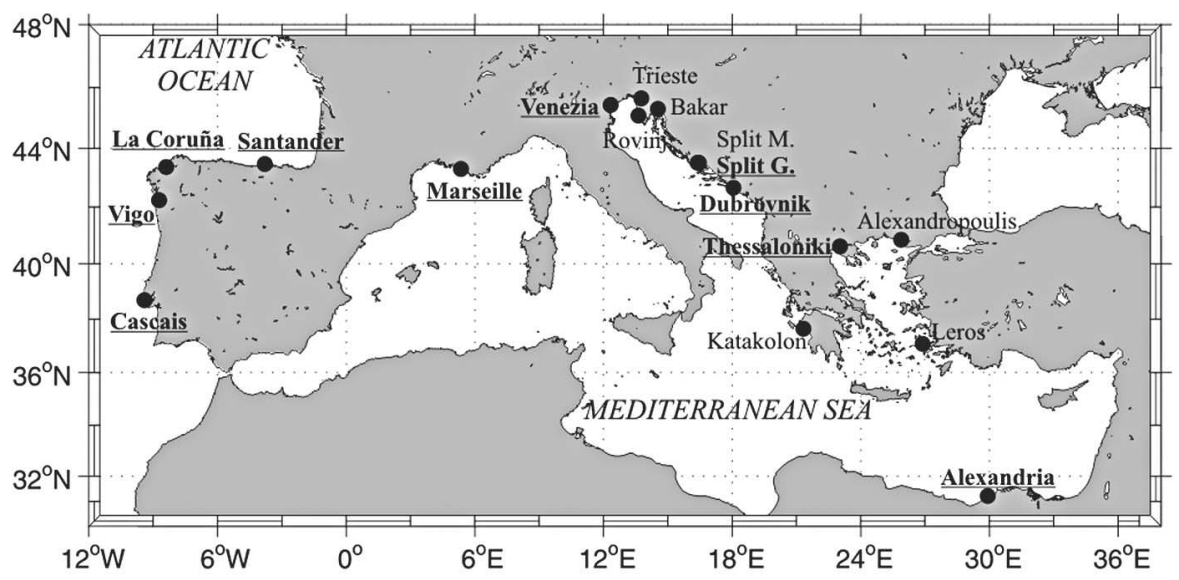

Figure 1. Contemporary tide gauge records in southern Europe longer than 40 years with at least $80 \%$ of valid data: name, Permanent Service for Mean Sea Level (PSMSL) identification, location, time span, and percentage of valid data. Stations highlighted in italic were discarded for the reasons explained in the text. 


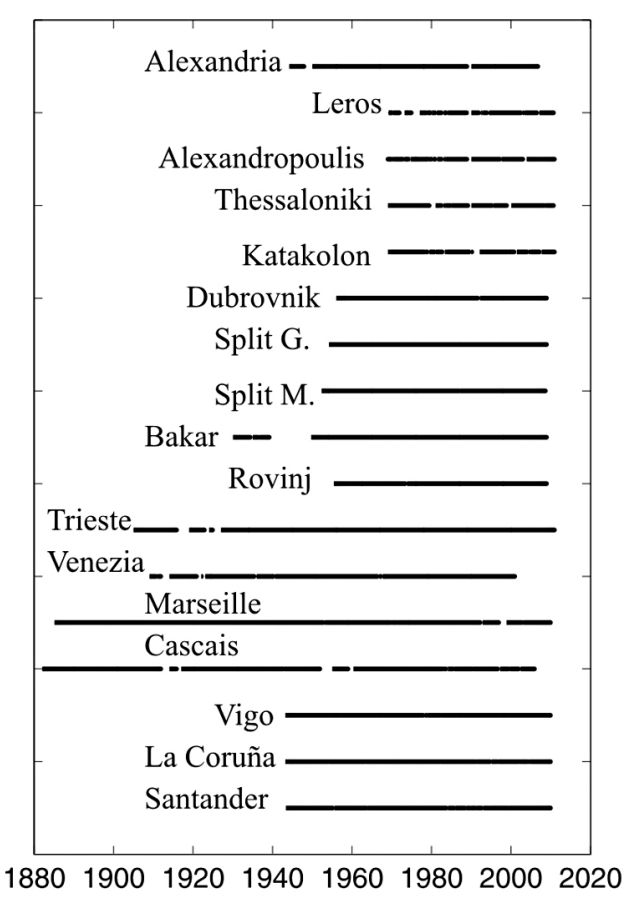

Figure 2. Tide gauge data span according to PSMSL data holdings as of May 2011, except Alexandria, Egypt, and Cascais, Portugal, which were updated from individuals (see text).

study, we concentrated on average linear rates of vertical land movements, assuming thus any nonlinearity was negligible over the multidecadal tide gauge data span considered. For completeness, we summarize here the advanced approach and the solution algorithm adopted.

[14] The rate of absolute (geocentric) vertical land movement $u_{i}$ at a tide gauge location $i$ is given by

$$
u_{i}=g_{i}-S_{i}^{A l t},
$$

where $g_{i}$ is the rate of absolute sea level change as provided by altimetry, and $S_{i}^{A l t}$ is the rate of relative sea level change as provided by tide gauges for the altimetric period. The implicit assumption is that internal drifts and errors in the observations from both sources are negligible.

[15] The altimetric period spans 17 years (up to 2010) and therefore the rate of vertical land movement estimated using the classical approach is strongly affected by interannual and decadal sea level signals, leading to uncertainties mostly of the order of 1-2 $\mathrm{mm} \mathrm{yr}^{-1}$ [e.g., Ray et al., 2010; Trisirisatayawong et al., 2011]. That is, the same order of magnitude, or even larger, than the sought-after climate-related signal itself.

[16] In order to reduce the uncertainty, the rate of relative vertical land movement between two nearby tide gauges $r u_{i j}$ (those where the absolute sea level signal can be considered to be the same) is introduced as follows:

$r u_{i j}=u_{i}-u_{j}=S_{j}^{T G}-S_{i}^{T G} \quad$ or alternatively $\quad r u_{i j}=u_{i}-u_{j}=S_{j-i}^{T G}$,

where $S_{i}^{T G}$ and $S_{j}^{T G}$ rates are computed for the long period covered by the tide gauge records (first option) and $S_{j-i}^{T G}$ from the differenced tide gauge time series (second option). The second option was chosen in this study (section 3.2).

[17] Equations (1) and (2) applied to $n$ locations can be expressed in matrix form as the following equations (3) and (4), respectively,

$$
G \cdot m=d,
$$

where $G$ is the $n \times n$ identity matrix, $m$ is the vector of unknowns, and $m$ and $d$ are defined as follows:

$$
\begin{aligned}
& m=\left(\begin{array}{l}
u_{1} \\
u_{2} \\
u_{3} \\
\cdots \\
u_{n-1} \\
u_{n}
\end{array}\right) \\
& \left.F \cdot m=h, \begin{array}{l}
g_{1}-S_{1}^{A l t} \\
g_{2}-S_{2}^{A l t} \\
g_{3}-S_{3}^{A l t} \\
\cdots \\
g_{n-1}-S_{n-1}^{A l t} \\
g_{n}-S_{n}^{A l t}
\end{array}\right) \\
& F,
\end{aligned}
$$

with $F$ being a $p \times n$ matrix and $p$ being the number of constraint equations representing the pairs of tide gauge stations considered. For example, if only adjacent tide gauges are used:

$$
F=\left(\begin{array}{cccccc}
1 & -1 & 0 & 0 & \cdots & 0 \\
0 & 1 & -1 & 0 & \cdots & 0 \\
0 & 0 & 1 & -1 & \cdots & 0 \\
\cdots & & & & & \cdots \\
0 & 0 & 0 & \cdots & 1 & -1
\end{array}\right) \text { and } h=-F\left[\begin{array}{c}
S_{1}^{T G} \\
S_{2}^{T G} \\
S_{3}^{T G} \\
\cdots \\
S_{n-1}^{T G} \\
S_{n}^{T G}
\end{array}\right]
$$

The matrix $F$ is defined depending on the pairs of stations selected, to which equation (2) is applied. They are not necessarily adjacent and can be located at long distances from each other as long as the rates of absolute sea level rise are not expected to differ. In this study, the number and form of the constraints were defined according to the observed correlations and overlapping periods between pairs of stations as discussed in section 3.3.

[18] Equation (3) represents an inverse problem subject to the constraints given by equation (4). The classical approach that only considers the satellite altimetry data period is restricted to solving equation (3). The system formed by (3) and (4) can be solved by implementing the constraints using Lagrange multipliers [Menke, 1989]. The resulting system in matrix form is then as follows:

$$
\left[\begin{array}{cc}
G^{T} G & F^{T} \\
F & 0
\end{array}\right]\left[\begin{array}{c}
m \\
\lambda
\end{array}\right]=\left[\begin{array}{l}
d \\
h
\end{array}\right] .
$$

Equation (5) is a linear system of the form $A \cdot X=Y$ whose simple least squares solution is given by

$$
X=\left(A^{T} A\right)^{-1}\left(A^{T} Y\right),
$$

[19] The first $n$ elements of $X$ correspond to the $m$ vector while the other $p$ elements are the Lagrange multipliers. According to the general least squares theory, the uncertainties of $m$ can be estimated from the diagonal terms of the associated covariance matrix $\left(\left(A^{T} W A\right)^{-1}\right)$, where $W$ is given by

$$
W=\operatorname{diag}\left[\begin{array}{c}
E_{S g}^{2} \\
E_{S}^{2}
\end{array}\right]^{-1},
$$




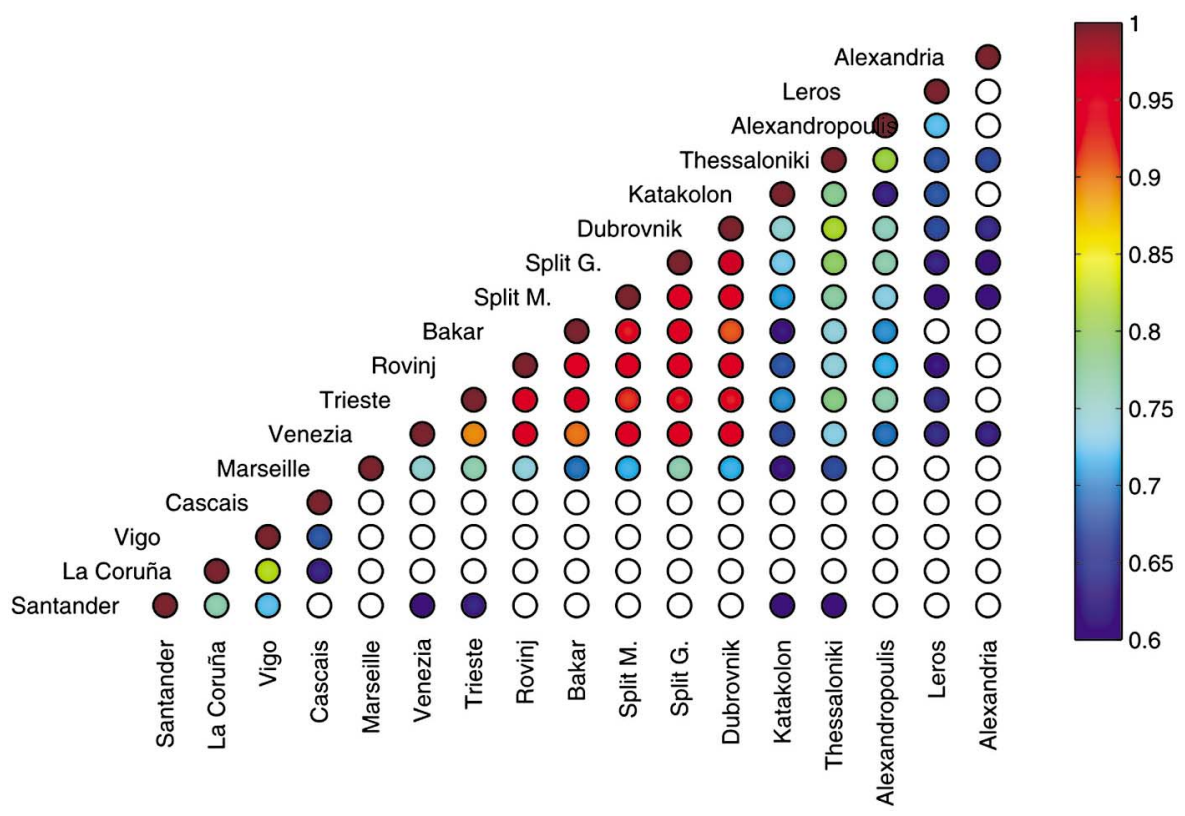

Figure 3. Correlation coefficients between pairs of monthly tide gauge time series used in this study (annual and semiannual cycles removed prior to calculation). Values inferior to the adopted criteria of 0.6 are not displayed (white circles). Although there are high correlations between Santander and some of the Mediterranean tide gauges, these pairs were not included in the constraint equations (the Mediterranean and Atlantic areas were considered separately, see text).

where $E_{\mathrm{Sg}}$ is the standard error of the linear trend of the differences between tide gauge and satellite altimetry data and $E_{\mathrm{S}}$ the standard error of the linear trend of the differences between pairs of tide gauges.

\subsection{Implementation Options and Assumption}

[20] There are different ways of determining the satellite altimetry time series associated with each tide gauge record. For instance, the most correlated grid point or the closest grid point to the tide gauge site can be adopted when interpolated altimetry fields are used, as it is the case in this work. Alternatively, an average of the closest altimetric data within a defined radius of influence may also be considered. The first option was adopted for the results presented throughout this study, that is, the most correlated grid point. Correlations between monthly values of tide gauge and altimetry data were computed among the grid points around the tide gauge sites using detrended and deseasoned time series. The seasonal signals were removed from the original monthly time series simply by subtracting the estimates obtained from the least squares adjustment of seasonal sinusoids with annual and semiannual periods. The other options for constructing the satellite altimetry time series were also considered, and differences in the estimated rates of vertical land movements are discussed later on in the results section.

[21] In this study, all the rates were computed from the series of monthly sea level differences built for the common periods, either between the tide gauge and altimetry data or between the pair of tide gauge records. In addition, it is worth noting that the seasonal signals were removed, as it was mentioned above, prior to the computations of these series of differences as their presence could skew the rate estimates of the shortest series stemming from the satellite altimetry data. A robust linear regression [Street et al., 1988] was applied to derive the rates and standard errors of the differences.

[22] As pointed out by Kuo et al. [2004], the novel approach applies under the assumption that all tide gauges display coherent long-term absolute sea level variations, particularly valid in lakes and semienclosed seas. The Mediterranean Sea is a semienclosed sea where previous studies have proven that this assumption holds [Tsimplis et al., 2008; Calafat and Gomis, 2009]. In addition, high coherent patterns of sea level change at interdecadal scales were also reported along the Atlantic northern Iberian coasts by Marcos et al. [2005]. We have therefore explored the novel approach in these two regions, with the Atlantic Iberian region appearing as a tentative exercise toward open oceanic conditions where the assumption may not hold.

\subsection{Refining the Tide Gauge Selection}

[23] The selection of pairs of tide gauge stations is based on two additional criteria to build the set of constraint equation (2): the overlapping period between each pair of records was required to be at least of 30 years and the correlation of the time series (detrended and deseasoned) of at least 0.6. Given the length of the tide gauge records and the requirement that they had to be contemporary to satellite altimetry, the first criterion was almost always fulfilled. On the other hand, the second criterion revealed differences among regions (Atlantic and Mediterranean) due to their distinct oceanographic conditions. Figure 3 represents the correlation coefficients for each pair of stations. Only those larger than 0.6 are plotted (all of them are statistically significant at the $95 \%$ confidence level); otherwise, they are blanked. It is clear from Figure 3 that Atlantic and 
Table 2. Geocentric Vertical Land Movements at the Selected Stations Combining Tide Gauges and Satellite Altimetry Data, Either From the Classic or the Advanced Approach ${ }^{\mathrm{a}}$

\begin{tabular}{lcccc}
\hline & $\begin{array}{c}\text { Altimeter }-\mathrm{TG} \\
\text { Classical Approach } \\
\text { Station (PSMSL) }\end{array}$ & $\begin{array}{c}\text { Altimeter }-\mathrm{TG} \\
\text { This Study/Advanced } \\
\text { Approach }^{\mathrm{c}} \text { (All Data) }\end{array}$ & $\begin{array}{c}\text { GPS }^{\mathrm{d}} \\
\text { (ULR Solution) }\end{array}$ & GIA (SELEN) \\
\hline Santander I & $-1.62 \pm 0.43$ & $0.91 \pm 0.34$ & $-0.09 \pm 0.23$ & $-0.55 \pm 0.26$ \\
La Coruña I & $0.19 \pm 0.60$ & $0.73 \pm 0.33$ & $-2.19 \pm 1.82$ & $-0.80 \pm 0.26$ \\
Vigo & $3.64 \pm 0.64$ & $0.57 \pm 0.33$ & & $-0.70 \pm 0.31$ \\
Cascais & $0.43 \pm 0.66$ & - & $0.18 \pm 0.16$ & $-0.62 \pm 0.22$ \\
Marseille & $-0.23 \pm 0.45$ & $0.17 \pm 0.20$ & $-0.04 \pm 0.25$ & $-0.59 \pm 0.19$ \\
Venezia (PDS) & $-2.03 \pm 1.32$ & $-1.22 \pm 0.19$ & $1.40 \pm 3.06$ & $-0.43 \pm 0.19$ \\
Trieste & $-0.31 \pm 0.39$ & $0.30 \pm 0.19$ & & $-0.41 \pm 0.19$ \\
Rovinj & $1.95 \pm 0.42$ & $0.75 \pm 0.19$ & & $-0.46 \pm 0.20$ \\
Bakar & $0.03 \pm 0.50$ & $0.43 \pm 0.18$ & & $-0.45 \pm 0.20$ \\
Split Marjana & $-0.44 \pm 0.44$ & $0.61 \pm 0.18$ & & $-0.58 \pm 0.20$ \\
Split Gradska Luka & $-0.69 \pm 0.45$ & $0.70 \pm 0.18$ & $-0.92 \pm 0.31$ & $-0.60 \pm 0.17$ \\
Dubrovnik & $-0.50 \pm 0.38$ & $0.32 \pm 0.18$ & & $-0.84 \pm 0.23$ \\
Katakolon & $0.63 \pm 0.47$ & $0.06 \pm 0.21$ & $-0.63 \pm 0.22$ \\
Thessaloniki & $-1.38 \pm 0.47$ & $-1.96 \pm 0.25$ & & $-0.64 \pm 0.20$ \\
Alexandroupolis & $0.01 \pm 0.47$ & $0.02 \pm 0.28$ & & $-0.80 \pm 0.19$ \\
Leros & $3.63 \pm 0.51$ & $1.28 \pm 0.35$ & $-0.1 \pm 0.5$ & $-0.51 \pm 0.07$ \\
Alexandria & $0.37 \pm 0.70$ & $-0.40 \pm 0.23$ & & \\
\hline
\end{tabular}

${ }^{\mathrm{a}} \mathrm{TG}$, tide gauge. For comparison, GPS velocities nearby the tide gauge are given where available from the latest ULR solution, as well as GIA predictions from SELEN model (only the crustal displacement term for rigorous comparison, see text). Values are

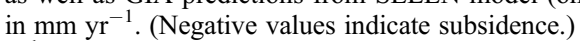

${ }^{b}$ Estimated vertical motions obtained by differencing satellite-based sea level data (AVISO) and tide gauge data over the same data span (1992-2010) using a classical approach [e.g., Cazenave et al., 1999].

${ }^{\mathrm{c}}$ Advanced approach. Estimated vertical motions obtained by applying the approach described by Kuo et al. [2004] using the satellite altimetry data for 1992-2010 and the tide gauge data over the entire data span available at each tide gauge (Table 1).

${ }^{\mathrm{d}}$ GPS vertical velocities obtained from the ULR consortium [Santamaría-Gómez et al., 2011]. Uncertainties were estimated taking into account the noise content in the GPS position time series.

Mediterranean Sea stations display a different behavior. Actually, this is not a surprise and it further supported our separate treatment of the two regions considered in this study, that is, no constraint equation was introduced linking stations from the Atlantic and Mediterranean Sea areas. All Adriatic records show correlation coefficients over 0.8. Interestingly, Alexandria tide gauge record is correlated with stations in the Adriatic, but not with all stations in the Aegean, despite its closest proximity.

\section{Results}

[24] Table 2 provides the estimates of vertical land movements at the selected tide gauge sites using both the classical approach (column 2) and the advanced approach (column 3). For comparison, GPS vertical velocities from the latest reanalyzed solution of ULR consortium [Santamaría-Gómez et al., 2011] are reported where available (column 4). The predictions from the glacial isostatic adjustment (GIA) model SELEN [Spada and Stocchi, 2007] as calculated by Tsimplis et al. [2011] are given in the last column, only the crustal displacement term here for a rigorous comparison. The geoid rate term of GIA predictions should be considered in addition to the crustal displacement term when investigating the climate contributions to tide gauge observed sea level change, assuming GIA is the predominant mechanism causing vertical motion for the tide gauge benchmark (section 5.2). Positive rate values indicate land uplift, while negative values indicate land subsidence.

[25] The classical approach yielded formal error bars between 0.4 and $1.3 \mathrm{~mm} \mathrm{yr}^{-1}$, in agreement with the literature using this approach in the Mediterranean Sea [e.g., Garcia et al., 2007] and the longest data span used here. The poorest error was found corresponding to the shortest altimetry record of 8 years at Venezia. The median error of $0.5 \mathrm{~mm} \mathrm{yr}^{-1}$ reduced to $0.2 \mathrm{~mm} \mathrm{yr}^{-1}$ when moving from the classical to the advanced approach. Most striking was that the vertical land movement estimates were significantly modified with differences larger than $3 \mathrm{~mm} \mathrm{yr}^{-1}$.

[26] Consequently, the sensitivity of both approaches was investigated, for instance, by examining the results using the options of altimetry data selection mentioned in the previous section, that is, using the time series of the closest grid point, or the most correlated point, or the average within a $1^{\circ}$ radius around the tide gauge stations. When the closest grid point of the altimetry data was used instead of the most correlated, the estimates of vertical land movement changed about $0.22 \mathrm{~mm} \mathrm{yr}^{-1}$ on average at the Atlantic stations using Kuo et al. [2004] approach, and as little as 0.15 to $0.16 \mathrm{~mm} \mathrm{yr}^{-1}$ at the Mediterranean Sea stations. All the differences were within the $1 \sigma$ formal error bars of the advanced approach. By contrast, in the case of the classical approach, the differences ranged from 0.7 to $0.9 \mathrm{~mm} \mathrm{yr}^{-1}$ in both the Atlantic and Mediterranean Sea, that is, consistent but larger than the $1 \sigma$ error bars. Similarly, when a spatial average of altimetry data within a radius of $1^{\circ}$ was used, differences were found around $0.26 \mathrm{~mm} \mathrm{yr}^{-1}$ at the Atlantic stations using the advanced approach. They were as insignificant as 0.08 to $0.09 \mathrm{~mm} \mathrm{yr}^{-1}$ in the Mediterranean Sea, whereas the classical approach yielded differences of 0.4 to $0.5 \mathrm{~mm} \mathrm{yr}^{-1}$. In the latter case, the differences were also within the $1 \sigma$ formal error bars, although 5 times larger than in the advanced Kuo et al. approach. 

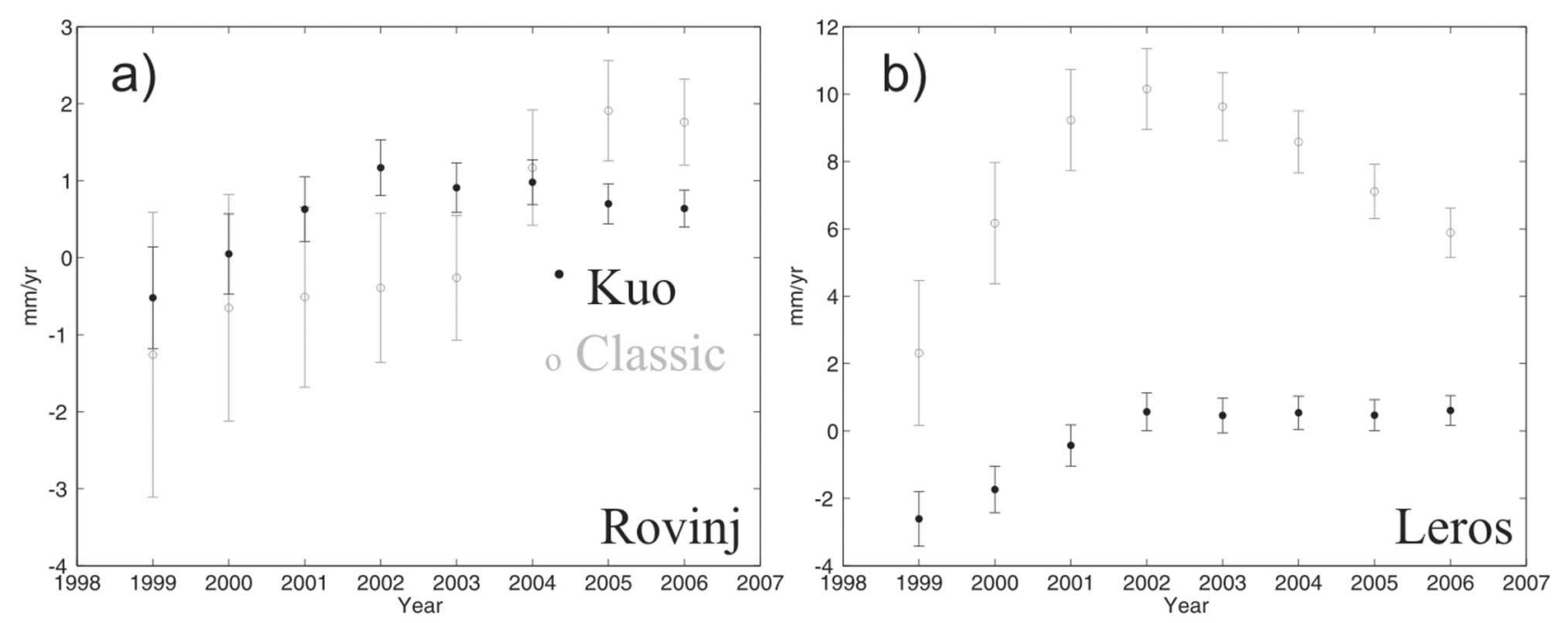

Figure 4. Estimates of vertical land movements resulting from the advanced Kuo et al. [2004] approach and from the classical approach at (a) Rovinj (Adriatic) and (b) Leros (Aegean) using different durations of common tide gauge and altimetry data. The $x$ axis corresponds to the last year considered while increasing the time series duration.

[27] To further assess the robustness of the advanced approach, we examined the effect of removing one tide gauge station, consecutively different, from the total set of stations. In the Atlantic area, the effect on the rate of vertical land movements was smaller than $0.1 \mathrm{~mm} \mathrm{yr}^{-1}$, except when the longest tide gauge record of Cascais was removed. In that case, the vertical land movement estimates of the rest of the sites decreased $0.4 \mathrm{~mm} \mathrm{yr}^{-1}$. The case of Cascais is discussed in further detail later on in the discussion section. In the Mediterranean Sea, the removal of any of the tide gauge stations resulted in changes always smaller than $0.1 \mathrm{~mm} \mathrm{yr}^{-1}$, with only one exception (Trieste). When Trieste was removed, the vertical land movement estimates of the adjacent stations of Venezia and Marseille changed by

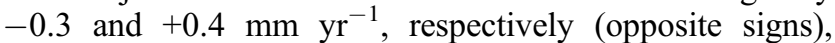
whereas the rest and distant stations changed as little as 0.1 to $0.2 \mathrm{~mm} \mathrm{yr}^{-1}$. The reason for this particular sensitivity to Trieste absence is likely related to its long-range spatial representativeness in sea level variations already noted by Woodworth [2003] when buddy checking the Mediterranean Sea tide gauge records. Trieste shows a high-quality record longer than 100 years, thus providing better constraints to Venezia than Rovinj, which is barely complying with the 30 year overlapping tide gauge data criteria. In this respect, considering that Venezia tide gauge data only overlap 8 years with altimetry data and that the station is known to be subject to a nonlinear behavior due to subsidence [e.g., Woodworth, 2003], whether using a long (Trieste) or short (Rovinj) nearby record likely explains the observed difference at Venezia, and the subsequent impact at Marseille.

[28] The overlapping duration between the tide gauge and satellite altimetry data is of major importance. A test was performed to check the robustness of both approaches when different overlapping durations were used, ranging from only 7 years up to 14 years, that is, for time series finishing between 1999 and 2006. The advanced approach results converged as soon as 8-9 years of overlapping data were used. By contrast, when the classical approach was applied, instead, the resulting rates of vertical land movement did not stabilize using longer durations. They also displayed much larger rate uncertainties. Figure 4 illustrates this typical behavior at Rovinj and Leros sites. Therefore, the requirement of at least 8 years of overlapping tide gauge and altimetry data was chosen in our study.

\section{Discussion}

[29] To further assess the performance of the advanced Kuo et al. [2004] method and to appraise to what extent the vertical land movements are responsible for the observed geographic variability in the rates of relative sea level change as observed by the tide gauges along the coasts of southern Europe, we corrected the tide gauge trends for the vertical land movements estimated from the various approaches (Table 3). The uncertainties were obtained by simply propagating the formal errors of each method assuming the variables were random and independent as they resulted from external data or different procedures.

[30] Buble et al. [2010] point out that relative sea level change for the Adriatic has been investigated using a variety of techniques from which no general agreement has arisen, even though it might be expected that the geographic variability in the rate of climate-related sea level change should be negligible in such a relatively small and isolated body of water. Most of the past estimates for Adriatic tide gauge trends were reported by these authors to differ from one station to another with a standard deviation of $0.8 \mathrm{~mm} \mathrm{yr}^{-1}$ about the mean, which we confirmed to be similar $(0.7 \mathrm{~mm}$ $\mathrm{yr}^{-1}$ ) in our sample of Adriatic stations (Table 3, column 2). It was therefore interesting to note that by correcting these tide gauge trends using the advanced approach (Table 3, column 5), the standard deviation was reduced from 0.7 to $0.1 \mathrm{~mm} \mathrm{yr}^{-1}$, whereas for the classical approach (column 4) the standard deviation slightly increased to $0.8 \mathrm{~mm} \mathrm{yr}^{-1}$. These results were further confirmed in other regions. For instance, the subset of Greek stations had their standard 
Table 3. Rates of Sea Level Change From Tide Gauge Records and Corrected for Land Movements From Different Solutions: Combination of Altimetry and Tide Gauge Data Using the Classical and the Advanced Approaches, GPS, and GIA ${ }^{\mathrm{a}}$

\begin{tabular}{|c|c|c|c|c|c|}
\hline Station (PSMSL) & No Correction & Altimeter - TG (Classic) & Altimeter - TG (Advanced) & GPS-Corrected (ULR Solution) & GIA-Corrected (SELEN) \\
\hline Santander I & $2.07 \pm 0.13$ & $0.45 \pm 0.45$ & $2.98 \pm 0.36$ & $1.97 \pm 0.26$ & $1.52 \pm 0.29$ \\
\hline La Coruña I & $2.21 \pm 0.14$ & $2.40 \pm 0.62$ & $2.94 \pm 0.36$ & $0.02 \pm 1.83$ & $1.42 \pm 0.30$ \\
\hline Vigo & $2.35 \pm 0.14$ & $5.99 \pm 0.66$ & $2.92 \pm 0.36$ & & $1.65 \pm 0.34$ \\
\hline Cascais & $1.29 \pm 0.04$ & $1.72 \pm 0.66$ & - & $1.14 \pm 0.19$ & $0.35 \pm 0.24$ \\
\hline Marseille & $1.22 \pm 0.04$ & $0.99 \pm 0.45$ & $1.39 \pm 0.20$ & $1.18 \pm 0.25$ & $0.63 \pm 0.19$ \\
\hline Venezia (PDS) & $2.45 \pm 0.09$ & $0.42 \pm 1.32$ & $1.24 \pm 0.21$ & $3.85 \pm 3.06$ & $2.02 \pm 0.21$ \\
\hline Trieste & $1.28 \pm 0.07$ & $0.97 \pm 0.40$ & $1.58 \pm 0.20$ & & $0.87 \pm 0.20$ \\
\hline Rovinj & $0.53 \pm 0.17$ & $2.48 \pm 0.45$ & $1.27 \pm 0.25$ & & $0.07 \pm 0.26$ \\
\hline Bakar & $1.03 \pm 0.12$ & $1.06 \pm 0.51$ & $1.46 \pm 0.22$ & & $0.46 \pm 0.26$ \\
\hline Split Marjana & $0.64 \pm 0.16$ & $0.20 \pm 0.47$ & $1.25 \pm 0.24$ & & $0.06 \pm 0.26$ \\
\hline Split G. Luka & $0.64 \pm 0.16$ & $-0.05 \pm 0.48$ & $1.33 \pm 0.24$ & & $0.06 \pm 0.26$ \\
\hline Dubrovnik & $1.02 \pm 0.16$ & $0.52 \pm 0.41$ & $1.33 \pm 0.24$ & $0.1 \pm 0.35$ & $0.42 \pm 0.23$ \\
\hline Katakolon & $1.97 \pm 0.22$ & $2.60 \pm 0.52$ & $2.03 \pm 0.30$ & & $1.13 \pm 0.32$ \\
\hline Thessaloniki & $3.88 \pm 0.24$ & $2.50 \pm 0.53$ & $1.93 \pm 0.34$ & & $3.26 \pm 0.33$ \\
\hline Alexandroupolis & $2.05 \pm 0.27$ & $2.06 \pm 0.54$ & $2.07 \pm 0.39$ & & $1.42 \pm 0.34$ \\
\hline Leros & $0.93 \pm 0.24$ & $4.56 \pm 0.56$ & $2.21 \pm 0.42$ & & $0.14 \pm 0.31$ \\
\hline Alexandria & $1.81 \pm 0.12$ & $2.18 \pm 0.74$ & $1.41 \pm 0.25$ & $1.64 \pm 0.51$ & $1.23 \pm 0.14$ \\
\hline
\end{tabular}

${ }^{\mathrm{a}}$ Only the crustal displacement term for rigorous comparison (see text). TG, tide gauge. Values are in $\mathrm{mm}_{\mathrm{yr}}{ }^{-1}$.

deviation also considerably reduced from 1.2 to $0.1 \mathrm{~mm} \mathrm{yr}^{-1}$. By contrast, the classical approach barely modified the agreement showing a standard deviation of around $1.1 \mathrm{~mm} \mathrm{yr}^{-1}$.

[31] It is unlikely that independent random variables exhibit the same mean values to within a precision higher than the individual standard errors, whereas the method has shown to allow differences occurring up to around $0.7 \mathrm{~mm} \mathrm{yr}^{-1}$ within a given region (e.g., Greek stations compared to others in the Mediterranean Sea). We interpret the very low probability of achieving close agreement by chance between corrected rates of sea level change among stations lying in different oceanic and geographic contexts as an indication of the high performance of the advanced Kuo et al. [2004] approach to estimate accurate vertical land movements at tide gauges. A graphical comparison of the relative performances of the various approaches is presented in Figure 5 where the corrected rates of sea level change from the advanced approach enable delineating regional patterns along the coastlines. These patterns are examined in detail later on, whereas the results from the GIA- and GPS-corrected rates of sea level change are discussed below.

\subsection{GPS- and GIA-Corrected Rates of Sea Level Change}

[32] As previously noted, availability of GPS data is currently limited at tide gauges [Merrifield et al., 2010]. The available data are further limited when high-accurate submillimeter per year vertical GPS velocities are required from state-of-the-art reanalyzed solutions using a global-scale strategy with the same models and corrections over the complete data span. Where available, the GPS velocities from the recently published solution by Santamaria-Gómez et al. [2011] are reported in Table 2. The formal velocity uncertainties were recalculated using the stochastic model that was best representing the time-correlated noise process in the GPS position time series following the Maximum Likelihood Estimation criteria and technique described by Williams [2008].

[33] From Table 2, it is clear that the classical approach performed poorly relative to the GPS, whereas general agreement was found for the advanced approach within the associated error bars. However, this general agreement should be appraised as a rudimentary comparison in various respects. Only six stations were available once Cascais was discarded (see discussion in the next section). Furthermore, two of them (La Coruña and Venezia) displayed large GPS velocity uncertainties stemming from the adopted random walk stochastic process, which conservatively characterized the true error in the vertical velocity estimates. A close examination into their GPS position time series (which can be downloaded from http://www.sonel.org/-GPS-Solutions-. html) clearly showed the presence of spurious signals that prevented us from deriving accurate estimates of true vertical land movement at these sites yet.

[34] There are a number of potential problems that may explain spurious signals at a particular location like Venezia causing systematic errors in the GPS solutions that need to be understood. These include instrumental errors, unrecorded changes or updates in the equipment, and changes in the configuration of the proximity of the instrument [e.g., King and Watson, 2010; King et al., 2011]. The Cascais and Dubrovnik sites showed statistically significant differences between the advanced approach and the GPS solution. Several limitations were noted at Dubrovnik station, which may explain the disagreement. First, the GPS station was decommissioned for a relatively long period of time between 2006.0 and 2007.5 , that is, 1.5 years or $20 \%$ of its time span from Santamaria-Gómez et al. [2011]. Second, and likely more important, is that the actual tide gauge and GPS antenna locales are not exactly the same, the distance being around $4 \mathrm{~km}$ here. This situation highlights a more general issue than the Dubrovnik case study, necessitating the assumption of relative stability as local geodetic connections between tide gauge benchmark and GPS antenna are mostly not available yet. It is a basic limitation that has repeatedly been underscored in previous sea level studies using GPS data [e.g., Nerem and Mitchum, 2002; Wöppelmann et al., 2007]. It could, however, easily be overcome if appropriate measures were taken following the international recommendations [e.g., Bevis et al., 2002; Blewitt et al., 2010; Merrifield et al., 2010]. Another basic assumption is that past local vertical land movement was at a steady rate over 

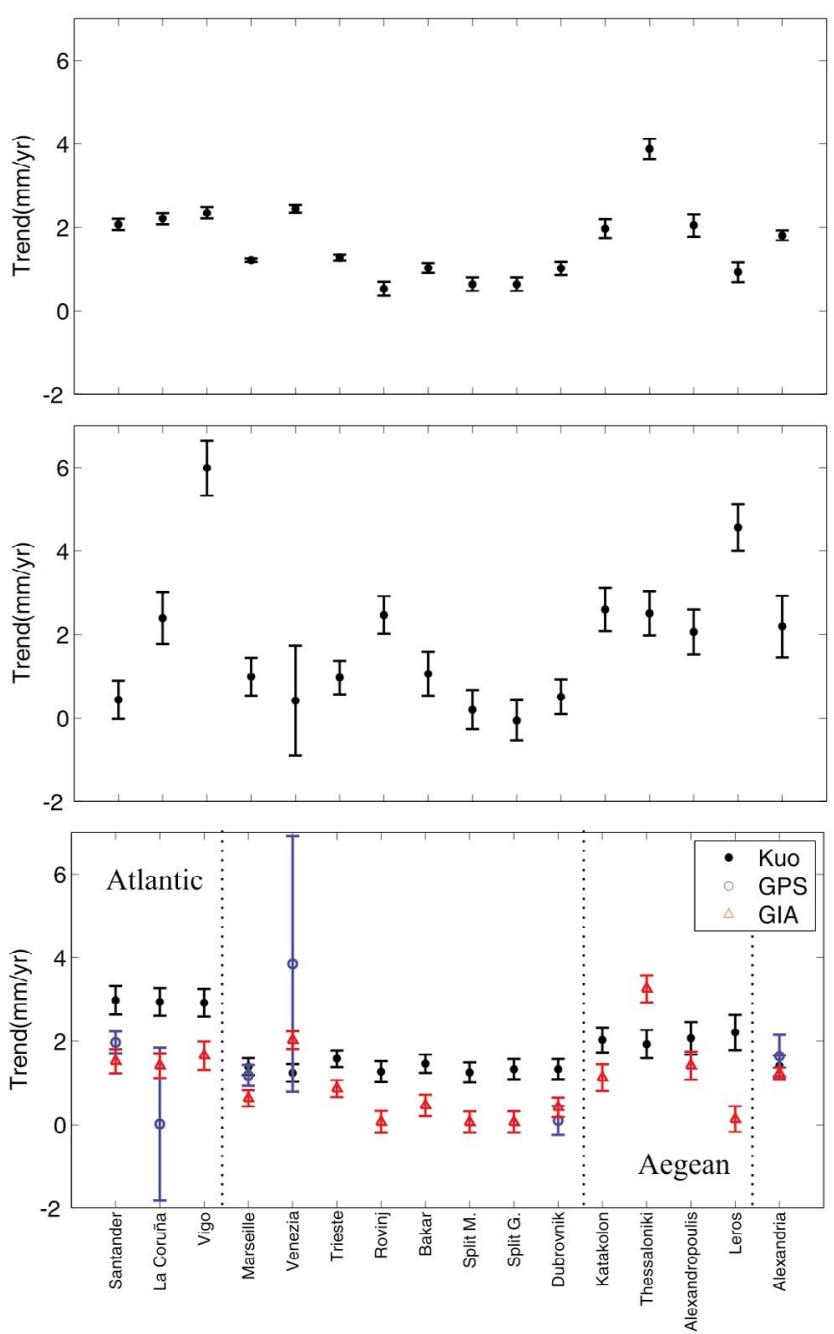

Figure 5. Rates of sea level change and uncertainties along the southern European coasts: (top) relative sea level trends from tide gauges; (middle) geocentric sea level trends using the classical approach; and (bottom) geocentric sea level trends using Kuo et al. [2004] approach (solid circle), GPS velocities (open circle), and GIA model predictions of the crustal displacement term (triangle). Note that the geoid rate term of GIA predictions should also be included when investigating the climate contributions to sea level change from tide gauges. Areas are separated by dashed vertical lines as Atlantic, Mediterranean, Adriatic, and Aegean. Values are

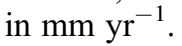

the decades to century timescale in which tide gauge was operational, and that it is continuing at the same steady rate over the GPS period. Both GPS-associated assumptions (limitations) are obviously avoided using land movement estimates from the advanced Kuo et al. [2004] approach.

[35] Figure 6 illustrates the comparison between the estimates obtained from the advanced Kuo et al. [2004] approach and either those obtained from the GPS solution by Santamaria-Gómez et al. [2011] or the GIA predictions from the SELEN model [Spada and Stocchi, 2007], only the radial crustal displacement term for a rigorous comparison with the other data types. Note that the geoid rate term of GIA predictions should also be included when investigating the climate contributions to sea level change from tide gauges (section 5.2). The SELEN model was preferred because of its focus on the southern Europe area and the comprehensive work that has recently been undertaken to assess its uncertainties [Tsimplis et al., 2011], exhaustively exploring the parameter space of mantle rheology and ice sheet chronologies. A detailed description of this SELEN model is given by Tsimplis et al. [2011], highlighting its most important features and including a comprehensive comparison with respect to the ICE5G-VM2 model of Peltier
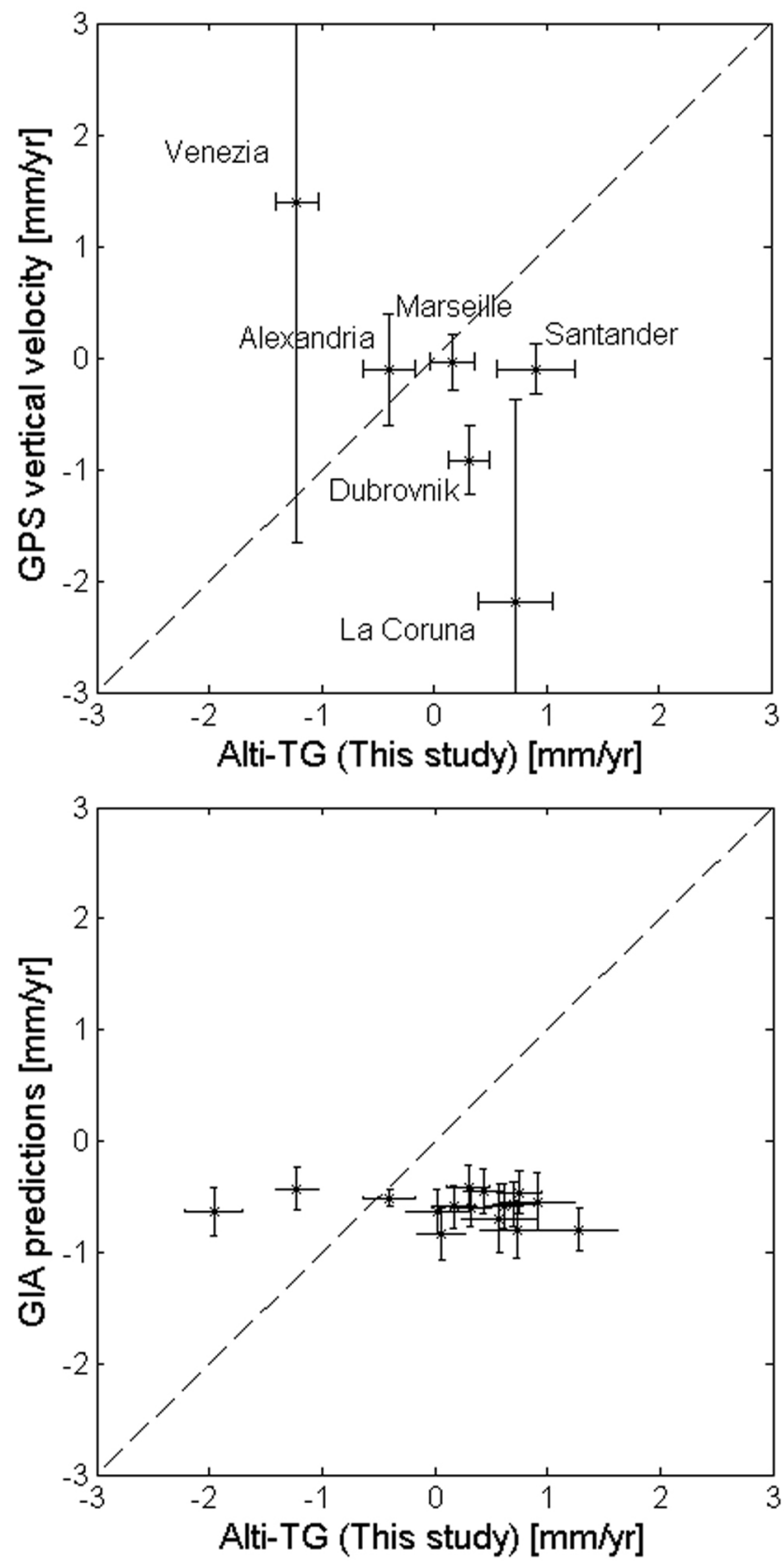

Figure 6. Vertical land movements derived from the advanced approach combining satellite altimetry and tide gauge data against (top) GPS vertical velocities at the six colocated stations and (bottom) GIA crustal displacement predictions. One $\sigma$ error bars are indicated. 
[2004]. Yet it only provides a rudimentary comparison as GIA process may only represent a portion of the observed land movements, especially in an active tectonic area such as the Mediterranean region [Emery and Aubrey, 1991]. For instance, Di Donato et al. [1999] found that in central Mediterranean the long-term vertical land movement due to active tectonics is comparable to GIA. In addition, several studies have pointed out that in the Mediterranean Sea some GIA models predict subsidence of 0.4 to $0.8 \mathrm{~mm} \mathrm{yr}^{-1}$, whereas others predict uplift of 0.2 to $0.3 \mathrm{~mm} \mathrm{yr}^{-1}$ [e.g., Woodworth, 2003; Buble et al., 2010]. As expected, the use of the SELEN model predictions (Table 3, column 3) resulted in as large regional standard deviations as not correcting the tide gauge trends for those predictions. This is illustrated in Figure 5c. Modeling work, beyond the scope of this study, would be required to determine whether a modification of the assumed viscosity structure or ice history could improve the fit of GIA models to our data.

\subsection{Spatially Consistent Areas}

[36] When the advanced Kuo et al. [2004] approach is used to eliminate linear vertical land movements from tide gauge records, the dispersion among absolute (geocentric) rates of sea level rise is clearly diminished (Table 3) as expected from the inherent assumption underscored in section 3.2, within the precision limit of the method up to $0.7 \mathrm{~mm} \mathrm{yr}^{-1}$ as shown by our results in the Mediterranean Sea. A close inspection of the differences to verify the assumption within a region proved worthwhile as it is discussed below. In addition, whereas the approach constrains the individual results to the same absolute sea level trend within a region, it does not imply that the same estimate will result in different regions, especially if these were treated separately as we did (section 3.3). Our results suggest, indeed, that there are two differentiated regions along the coasts of southern Europe in terms of absolute sea level rise: the Atlantic Iberian coast and the Mediterranean basin.

[37] Along the Atlantic Iberian coast, it was worth noting that the maximum impact observed from the sensitivity tests were of around $0.4 \mathrm{~mm} \mathrm{yr}^{-1}$ when including or not including the Cascais tide gauge record (section 4), that is, at the limit of what can be expected from the novel approach in terms of precision. In addition, keeping Cascais in the application of the approach in that region resulted in a vertical land movement of $1.7 \pm 0.3 \mathrm{~mm} \mathrm{yr}^{-1}$ (not shown in the tables). The estimate of such a large uplift at Cascais is most striking and unrealistic as no evidence has been reported so far for such a large site displacement at the location or its surroundings. The Kuo et al. [2004] approach and inherent assumption using sensitivity tests could then be regarded as useful for detecting anomalous trends in tide gauge records due to instrumental drifts or calibration errors. When Cascais station was discarded from our analysis, then rates of sea level rise along the Atlantic northern Iberian coast were consistently estimated at around $2.9 \mathrm{~mm} \mathrm{yr}^{-1}$ in northern Spain (Table 3).

[38] In the Mediterranean Sea, the longest tide gauge records spanning the entire 20th century suggest the rates of absolute sea level rise between $1.2 \pm 0.2 \mathrm{~mm} \mathrm{yr}^{-1}$ in Venezia and $1.6 \pm 0.2 \mathrm{~mm} \mathrm{yr}^{-1}$ in Trieste, while Marseille presents an intermediate rate of $1.4 \pm 0.2 \mathrm{~mm} \mathrm{yr}^{-1}$. These differences among nearby series, especially those between Venezia and
Trieste, which given their proximity are very unlikely to exist, were also attributed to the different time spans of the tide gauge records. In particular, the available Venezia record stops in year 2000. When the common period for all three records was used, namely 1909-2000, the resulting rates of sea level rise were within $1.5-1.6 \mathrm{~mm} \mathrm{yr}^{-1}$ for these locations. They were thus consistent, although the shorter overlapping with altimetry data increased significantly the uncertainties up to $0.5 \mathrm{~mm} \mathrm{yr}^{-1}$. On the basis of the longest records in Marseille, Venezia, and Trieste, we estimate that the rate of sea level change in the Mediterranean Sea since the beginning of the 20th century is of $1.4 \pm 0.2 \mathrm{~mm} \mathrm{yr}^{-1}$. This value is slightly larger than the generally accepted rate of 1.1-1.3 $\mathrm{mm} \mathrm{yr}^{-1}$ [Tsimplis and Baker, 2000; Marcos and Tsimplis, 2008]. However, previous studies have either considered GIA as the only source of vertical land movement or not accounted at all for such effects.

[39] Absolute (geocentric) sea level rise provided by Mediterranean stations observing since the 1950s onward is highly consistent with a value of $1.3 \pm 0.2 \mathrm{~mm} \mathrm{yr}^{-1}$, not statistically different from the aforementioned estimate of $1.4 \mathrm{~mm} \mathrm{yr}^{-1}$. These stations are all located in the Adriatic Sea: Rovinj, Split M., Split G., and Dubrovnik. The tide gauge record from Bakar displays a higher value of $1.6 \pm$ $0.2 \mathrm{~mm} \mathrm{yr}^{-1}$ because of its longer time span since 1930 . Alexandria, although located in southeastern Mediterranean Sea, also shows consistency with a rate of $1.4 \pm 0.3 \mathrm{~mm}$ $\mathrm{yr}^{-1}$ for a period starting in 1944 .

[40] Tide gauge stations in the Aegean Sea display rates of absolute sea level rise of around 1.9-2.2 $\mathrm{mm} \mathrm{yr}^{-1}$. All of them span the same period 1969-2010. In order to check whether these higher rates are due to the shorter observational period or on the contrary they reflect a truly higher sea level rise in this sub-basin, our analysis was repeated only considering data from 1969 to 2006 for all stations. The resulting trends of absolute sea level rise increased in the Adriatic up to $1.6-1.9 \mathrm{~mm} \mathrm{yr}^{-1}$, reaching thus similar values to those of the Aegean stations. These higher values obtained when shorter recent periods are considered are likely due to the fast sea level rise observed during the 1990s [Cazenave et al., 2001; Fenoglio-Marc, 2001]. However, the shorter periods also increase the uncertainties up to 0.4 $0.5 \mathrm{~mm} \mathrm{yr}^{-1}$ and the dispersion among the results.

[41] We conclude that the rates of sea level rise during the 20th century and during the last decades present consistent patterns everywhere in the Mediterranean Sea, once the vertical land movements of the sites where the tide gauges are grounded have been properly removed. The success of the methodology to separate the oceanic and the land contributions to observed rates of sea level rise at the coast was demonstrated despite the variety in magnitude, direction, and nature of the land movement processes occurring in the Mediterranean region [Emery and Aubrey, 1991; Tsimplis et al., 2011].

[42] When the common period for all stations (19692006) is used (and discarding Venezia because of its shorter length in common with satellite altimetry data), absolute rates of sea level rise averaged over the Mediterranean and Atlantic stations are of $1.7 \pm 0.2$ and $3.1 \pm 0.1 \mathrm{~mm} \mathrm{yr}^{-1}$, respectively. That is, Mediterranean Sea level rise is lower than the northern Iberian coast by $1.4 \mathrm{~mm} \mathrm{yr}^{-1}$. Note that the uncertainties now reflect the dispersion among stations, 
whereas each individual trend has its own standard error of $0.4-0.5 \mathrm{~mm} \mathrm{yr}^{-1}$. A lower value $\left(\sim 1 \mathrm{~mm} \mathrm{yr}^{-1}\right)$ was also found by Marcos and Tsimplis [2007] but for the shorter period 1960-2000. The observed differences of sea level rise between these two close regions were explored by quantifying two forcing mechanisms, namely the atmospheric forcing and the differential thermal expansion. These are reviewed below.

[43] The atmospheric contribution to sea level was obtained from the output of a barotropic regional ocean model forced by a downscaled reanalysis of wind and atmospheric pressure over southern Europe and spanning the period 1958-2008 (G. Jordà et al., The HIPOCAS hindcast of sea level residuals revisited, submitted to Scientia Marina, 2011). The closest grid point of the ocean model to each tide gauge was chosen as a representative of the atmospherically induced sea level. On average, the atmospheric contribution to sea level during 1969-2006 at Mediterranean stations is $-0.26 \pm 0.12 \mathrm{~mm} \mathrm{yr}^{-1}$, and it is only $0.0 \pm 0.1 \mathrm{~mm} \mathrm{yr}^{-1}$ at the Atlantic sites. The difference between the two areas was only slightly reduced.

[44] Concerning the differential thermal expansion between both regions, thermosteric sea level was estimated using a monthly gridded temperature global database covering the period 1945-2006 with a grid spacing of $1^{\circ} \times 1^{\circ}$ [Ishii and Kimoto, 2009]. Density anomalies caused by changing temperatures were integrated down to $700 \mathrm{~m}$ to compute thermosteric sea level. The average rate of change of thermosteric sea level in the Mediterranean basin for the period 1969-2006 was $0.5 \mathrm{~mm} \mathrm{yr}^{-1}$, while it was $0.0 \mathrm{~mm}$ $\mathrm{yr}^{-1}$ in a sector of the nearby Atlantic (this value appeared robust around the Iberian Peninsula when different areas were considered). Consequently, this factor cannot explain neither of the observed different rates.

[45] Most interestingly, the GIA-induced geoid change predicted from the SELEN model (not including the radial crustal uplift that is already taken into account from the Kuo et al. [2004] approach estimates) could neither explain the observed differences between the two regions. Indeed, the predictions ranged $0.30-0.38 \mathrm{~mm} \mathrm{yr}^{-1}$ at the Mediterranean stations and $0.40-0.44 \mathrm{~mm} \mathrm{yr}^{-1}$ at the Atlantic stations, predicting a decrease in sea level of similar magnitude in both regions. However, correcting for this specific effect, our geocentric rates of sea level change yielded an average rise of $1.7 \mathrm{~mm} \mathrm{yr}^{-1}$ over the past 70 years or so in the Mediterranean Sea, in agreement with previous estimates of global sea level rise [e.g., Church and White, 2011].

\subsection{Case Studies}

[46] Here we consider those stations exhibiting large ver-

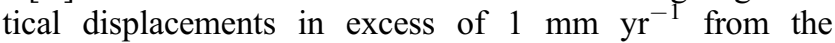
advanced approach (Table 2, column 3) with statistical significance at the $99 \%$ confidence level assuming Gaussian random variables. These stations are Venezia (Punta della Salute) in Italy $\left(-1.2 \pm 0.2 \mathrm{~mm} \mathrm{yr}^{-1}\right)$, Thessaloniki $(-2.0 \pm$ $\left.0.3 \mathrm{~mm} \mathrm{yr}^{-1}\right)$, and Leros $\left(+1.3 \pm 0.4 \mathrm{~mm} \mathrm{yr}^{-1}\right)$ in Greece. The Alexandria, Egypt, case study is also discussed because this large port city with more than one million inhabitants has been ranked 11 in terms of population exposed to coastal flooding in the 2070s and showing present-day exposure [Hanson et al., 2011].
[47] Delta regions have been given considerable attention in recent years as these coastal areas are subject to subsidence processes related to sedimentation that may exacerbate the exposure and risks to climate change-related sea level impacts. For instance, Hanson et al. [2011] considered an additional $0.5 \mathrm{~m}$ increase in relative sea level rise projections by 2070 s for large port cities established on delta regions with more than one million inhabitants. As a result of their analysis, Alexandria was ranked 11 in terms of population exposure to coastal flooding. However, our results have revealed that Alexandria is subject to a moderate rate of land subsidence $\left(-0.4 \pm 0.2 \mathrm{~mm} \mathrm{yr}^{-1}\right)$ around 20 times lower than the values adopted by Hanson et al. [2011] ( $0.5 \mathrm{~m}$ between 2005 and 2070) to assess the exposure of populations and assets in delta regions. The evidence for moderate subsidence in Alexandria is further supported by the $3 \mathrm{~km}$ distant GPS station (Table 2, column 4). Even though the associated error bar is currently as large as $0.5 \mathrm{~mm} \mathrm{yr}^{-1}$, the vertical GPS velocity estimate is incompatible with rates of subsidence in excess of $5 \mathrm{~mm} \mathrm{yr}^{-1}$. It also indicates that the observed low rate of subsidence is not restricted to the immediate tide gauge location. Additional work beyond the scope of this study would be useful to conclude on the areal extend of our result, for instance, using radar interferometry satellite techniques [e.g., Raucoules et al., 2008].

[48] Nonetheless, it is worth noting that past studies based on sediment borings [Stanley, 1990] have inferred a differential lowering of the northern Nile delta toward the northeast, which is in agreement with our result, from average rates of about $1 \mathrm{~mm} \mathrm{yr}^{-1}$ sinking nearby Alexandria to a maximum of about $5 \mathrm{~mm} \mathrm{yr}^{-1}$ in the Port Said area [Stanley, 1990]. This might appear as a surprising result in that deltas typically have high rates of subsidence, but it is locally consistent with the supplemental observation that deltaic mud ranges from $50 \mathrm{~m}$ at Port Said to nearly absent westward below the Alexandria coastal plain [Frihy, 2003]. Frihy [2003] suggests that the largest values of around $5 \mathrm{~mm}$ $\mathrm{yr}^{-1}$ subsidence reported on millennia timescale for Alexandria could likely be attributed to tectonic activity and abrupt subsidence episodes occurring during major earthquakes every few hundred years rather than to sedimentation. In between these seismic episodes, there might be essentially no subsidence from Alexandria westward.

[49] By contrast, the largest estimate of vertical displacement was observed at the second most populated and heavily industrialized city in Greece, Thessaloniki. With a population nearly reaching the one million inhabitants criteria of Hanson et al. [2011] study, Thessaloniki could be added to the list of other major coastal towns under the threat of marine invasion and flooding. Our negative estimate of around $2.0 \mathrm{~mm} \mathrm{yr}^{-1}$ is compatible with a peripheral subsidence of the Thessaloniki coastal plain, parts of which have been reported to be sinking at rates as high as $100 \mathrm{~mm} \mathrm{yr}^{-1}$ over the past decades [Stiros, 2001]. Pumping of groundwater for industrial usage can only account for a portion of the observed land movement as ongoing subsidence has been detected at rates in excess of $40 \mathrm{~mm} \mathrm{yr}^{-1}$ for 20 years after the aquifer exploitation stopped [Raucoules et al., 2008]. Consistently, Stiros [2001] has suggested a basinwide, long-term natural effect encompassing the whole of the Thessaloniki deltaic plain where subsidence due to 
pumping is superimposed only locally. In this complex context, our estimate may provide some information or at least some constraint on the extent and causes of this phenomenon in future work.

[50] It has long been established that Venezia is subsiding as a result of natural long-term compaction of deltaic sediments exacerbated by anthropogenic pumping of water wells between about 1940 and 1975 [e.g., Pirazzoli, 1987; Emery and Aubrey, 1991]. Our estimate of around $1.2 \mathrm{~mm} \mathrm{yr}^{-1}$ subsidence was found in close agreement with previously published results [e.g., Pirazzoli and Tomasin, 2002; Woodworth, 2003] if one considers these estimates as a cumulative averaged rate of vertical land movement over the past hundred years or so. A relatively wide range of rates could, of course, be derived from short periods of time including parts of the above-mentioned 1940-1975 period undergoing variable intensity of groundwater withdrawal.

[51] The most enigmatic results of our analysis come from the large uplift rate obtained at Leros $\left(1.3 \mathrm{~mm} \mathrm{yr}^{-1}\right)$. Leros Island is located on the south-east edge of the Aegean volcanic arc. Few bibliographic references were found on crustal deformation resulting from active tectonic processes at or nearby Leros Island. It was therefore difficult to assess or contrast our estimate of vertical land movement there. On the other hand, such results might help to locate areas of previously unknown uplift. In any event, it is worth mentioning that evidence for land uplift was found along the northern and western coast of the nearby Nisyros Island from geological proxies [Stiros et al., 2005], indicating an almost linear trend during the past 2000 years at a minimum rate of $1.7 \mathrm{~mm} \mathrm{yr}^{-1}$ comparable to that determined at Leros.

\section{Conclusions}

[52] Little success has been obtained so far to include the nonclimate contribution of vertical land movements from space geodetic techniques in projections of sea level rise relative to the land at the coast [Intergovernmental Panel on Climate Change, 2007]. Yet this information is crucial in appraising the exposure of populations and assets to future sea level impacts. A rudimentary attempt has recently been made by Hanson et al. [2011], attributing an additional $0.50 \mathrm{~m}$ increase in sea level projections for coastal cities lying on deltaic plains. However, the results of our analysis did not support such large rate of subsidence in the case study of Alexandria (Egypt). The advanced approach of Kuo et al. [2004] that we implemented along the coasts of the Mediterranean Sea and the northern Iberian Peninsula yielded accurate estimates of vertical land movements at tide gauge sites, thereby supplementing the current limitations of available GPS data at tide gauges. Whereas Alexandria showed a low rate of subsidence, the highest rate was found at Thessaloniki (Greece), which is a heavily industrialized coastal city that is nearly reaching 1 million inhabitants. Vertical land movements can thus represent an important nonclimate contribution to future sea level rise as significant, if not greater, than climate contributions. They need to be known accurately for robust projections of sea level change and subsequent assessment of its actual impact along the coasts. Poor knowledge on land movements may profoundly hamper sea level rise projections, and ultimately lead to expensive mistakes in coastal management policies.
[53] The impact of vertical land movements on the spatial variability of observed sea level trends at the coast was also explored along southern European coasts. Highly coherent regional patterns of sea level change were inferred along the Mediterranean Sea and Atlantic northern Iberian coasts, once the tide gauge trends were corrected for the vertical land movement estimates from the advanced Kuo et al. [2004] approach. It is unlikely that independent random variables exhibit the same mean values to within a precision higher than the individual standard errors by chance. We interpret the very low probability of achieving close agreement by chance between stations lying in different coastline contexts as an indication of the high performance of the advanced Kuo et al. approach to estimate accurate vertical land movements at tide gauges. These findings extend those of Kuo et al. [2004, 2008] in the Fennoscandia, Alaskan coasts, and Great Lakes. A surprising outcome was the significant high sea level rise along the Atlantic northern Iberian coast, whereas the Mediterranean Sea displayed a rate of sea level change in agreement with previous estimates of global sea level rise of around $1.7 \mathrm{~mm} \mathrm{yr}^{-1}$ over the past 70 years when correcting the geocentric sea level estimates for the GIA-induced geoid change predicted by SELEN model. Further investigations to identify the forcing factor should be undertaken, beyond the scope of the present study and our first attempts exploring the various climatology data available to us.

[54] Accurate determination of vertical land movements constitutes thus a key step toward identifying the various forcing factors contributing to sea level change at a particular coast, correctly quantifying their relative importance, and improving our understanding of the causes for robust predictions and full assessment of coastal vulnerability by sea level rise. In this line, of particular importance is to increase the number and geographical distribution of the continuous GPS observations at tide gauges. Much remains to be done, however, in spite of the known importance of vertical land movements at the coast. In the meantime, the advanced Kuo et al. [2004] approach represents a worthwhile accurate alternative that has proved its superiority to the classical approach of subtracting tide gauge trends from satellite altimetry. It was, however, interesting to note that the quotations of the Kuo et al. study, as far as our review could reach, ignored the novel technique itself, which optimally combines short-term altimetry and long-term tide gauge records in a simultaneous adjustment. It is thus hoped that this study will increase the interest for applying this technique in other geographic contexts, either for sea level studies or as a useful source of supplementary data for refining geodynamic studies.

[55] Acknowledgments. We would like to thank Gabriel Jordà for providing numerical simulations of atmospheric-induced sea levels and Anny Cazenave and Philip Woodworth for positive comments on an early version of the manuscript. We are particularly grateful to CK Shum for fruitful exchanges and helpful comments that improved the manuscript. Two other anonymous reviewers are also acknowledged for their constructive comments. The work presented in this article was supported by the French Research National Agency (ANR) through the CEP-2009 program (Project "Coastal Environmental Changes: Impact of sea LEvel rise" (CECILE) under grant ANR-09-CEP-001-01). It was also carried out within the framework of the project VANIMEDAT-2 (CTM2009-10163-C02-01), funded by the Spanish Marine Science and Technology Program and the E-Plan of the Spanish Government. Universitat de les Illes Balears provided a visiting professor grant for G. Wöppelmann, whereas M. Marcos acknowledges a "Ramon y Cajal" 
contract funded by the Spanish Ministry of Science. The altimetry data used herein were distributed by AVISO, with support from the French space agency CNES. Most tide gauge data were provided by the Permanent Service for Mean Sea Level (PSMSL). The SONEL data assembly center is also acknowledged for providing a comprehensive access to GPS data at tide gauges, with the support of many agencies (see http://www.sonel.org).

\section{References}

Bevis, M., W. Scherer, and M. Merrifield (2002), Technical issues and recommendations related to the installation of continuous GPS stations at tide gauges, Mar. Geod., 25, 87-99, doi:10.1080/014904102753516750.

Blewitt, G., et al. (2010), Geodetic observations and global reference frame contributions to understanding sea level rise and variability, in Understanding Sea Level Rise and Variability, edited by J. Church et al., pp. 256-284, Wiley-Blackwell, Chichester, U. K., doi:10.1002/9781444323276.ch9.

Buble, G., R. A. Bennett, and S. Hreinsdottir (2010), Tide gauge and GPS measurements of crustal motion and sea level rise along the eastern margin of Adria, J. Geophys. Res., 115, B02404, doi:10.1029/2008JB006155.

Calafat, F. M., and D. Gomis (2009), Reconstruction of Mediterranean sea level fields for the period 1945-2000, Global Planet. Change, 66, 225-234, doi:10.1016/j.gloplacha.2008.12.015.

Carrère, L., and F. Lyard (2003), Modeling the barotropic response of the global ocean to atmospheric wind and pressure forcing comparisons with observations, Geophys. Res. Lett., 30(6), 1275, doi:10.1029/2002GL016473.

Cazenave, A., K. Dominh, F. Ponchaut, L. Soudarin, J. F. Crétaux, and C. Le Provost (1999), Sea level changes from TOPEX-POSEIDON altimetry and tide gauges, and vertical crustal motions from DORIS, Geophys. Res. Lett., 26, 2077-2080, doi:10.1029/1999GL900472.

Cazenave, A., C. Cabanes, K. Dominh, and S. Mangiarotti (2001), Recent sea level changes in the Mediterranean Sea revealed by TOPEX/POSEIDON satellite altimetry, Geophys. Res. Lett., 28, 1607-1610, doi:10.1029/ 2000GL012628.

Church, J. A., and N. J. White (2011), Sea-level rise from the late 19th to the early 21 st century, Surv. Geophys., 32, 585-602, doi:10.1007/s10712011-9119-1.

Church, J., P. L. Woodworth, T. Aarup, and S. Wilson (Eds.) (2010), Understanding Sea Level Rise and Variability, Wiley-Blackwell, Chichester, U. K., doi:10.1002/9781444323276.

Di Donato, G., A. M. Negredo, R. Sabadini, and L. L. A. Vermeersen (1999), Multiple processes causing sea-level rise in the central Mediterranean, Geophys. Res. Lett., 26, 1769-1772, doi:10.1029/1999GL900258.

Douglas, B. C. (2001), Sea level change in the era of the recording tide gauge, in Sea Level Rise: History and Consequences, Int. Geophys. Ser., vol. 75, edited by B. Douglas et al., chap. 3, pp. 37-64, Academic, San Diego, Calif., doi:10.1016/S0074-6142(01)80006-1.

Emery, K. O., and D. G. Aubrey (1991), Sea Levels, Land Levels, and Tide Gauges, 237 pp., Springer, New York, doi:10.1007/978-1-4613-9101-2.

Fenoglio-Marc, L. (2001), Analysis and representation of regional sea-level variability from altimetry and atmospheric-oceanic data, Geophys. J. Int., 145, 1-18, doi:10.1046/j.1365-246x.2001.00284.x.

Frihy, O. E. (2003), The Nile delta-Alexandria coast: Vulnerability to sealevel rise, consequences and adaptation, Mitig. Adapt. Strategies Glob. Change, 8, 115-138, doi:10.1023/A:1026015824714.

Garcia, D., I. Vigo, B. F. Chao, and M. C. Martinez (2007), Vertical crustal motion along the Mediterranean and Black Sea coast derived from ocean altimetry and tide gauge data, Pure Appl. Geophys., 164, 851-863, doi:10.1007/s00024-007-0193-8.

Hanson, S., R. J. Nicholls, N. Ranger, S. Hallegatte, J. Corfee-Morlot, C. Herweijer, and J. Chateau (2011), A global ranking of port cities with high exposure to climate extremes, Clim. Change, 104, 89-111, doi:10.1007/s10584-010-9977-4.

Intergovernmental Panel on Climate Change (2007), Climate Change 2007. The Physical Science Basis: Working Group I Contribution to the Fourth Assessment Report of the IPCC, edited by S. Solomon et al., Cambridge Univ. Press, New York.

Ishii, M., and M. Kimoto (2009), Reevaluation of historical ocean heat content variations with time-varying XBT and MBT depth bias corrections, J. Oceanogr., 65, 287-299, doi:10.1007/s10872-009-0027-7.

King, M. A., and C. S. Watson (2010), Long GPS coordinate time series: Multipath and geometry effects, J. Geophys. Res., 115, B04403, doi: $10.1029 / 2009 J B 006543$

King, M. A., M. Bevis, T. Wilson, B. Johns, and F. Blume (2011), Monumentantenna effects on GPS coordinate time series with application to vertical rates in Antarctica, J. Geod., doi:10.1007/s00190-011-0491-x, in press.

Kuo, C. Y., C. K. Shum, A. Braun, and J. X. Mitrovica (2004), Vertical crustal motion determined by satellite altimetry and tide gauge data in Fennoscandia, Geophys. Res. Lett., 31, L01608, doi:10.1029/2003GL019106.
Kuo, C. Y., C. K. Shum, A. Braun, K. C. Cheng, and Y. Yi (2008), Vertical motion determined using satellite altimetry and tide gauges, Terr. Atmos. Ocean. Sci, 19, 21-35, doi:10.3319/TAO.2008.19.1-2.21(SA).

Letetrel, C., M. Marcos, B. Martin Miguez, and G. Wöppelmann (2010), Sea level extremes in Marseille (NW Mediterranean) during 1885-2008, Cont. Shelf Res., 30, 1267-1274, doi:10.1016/j.csr.2010.04.003.

Marcos, M., and M. Tsimplis (2007), Forcing of coastal sea level rise patterns in the North Atlantic and the Mediterranean Sea, Geophys. Res. Lett., 34, L18604, doi:10.1029/2007GL030641.

Marcos, M., and M. Tsimplis (2008), Coastal sea level trends in southern Europe, Geophys. J. Int., 175, 70-82, doi:10.1111/j.1365-246X.2008. 03892.x.

Marcos, M., D. Gomis, S. Monserrat, E. Alvarez-Fanjul, B. Perez, and G. García-Lafuente (2005), Consistency of long sea-level time series in the northern coast of Spain, J. Geophys. Res., 110, C03008, doi:10.1029/2004JC002522.

Menke, W. (1989), Geophysical Data Analysis: Discrete Inverse Theory, 289 pp., Academic, San Diego, Calif.

Merrifield, M., et al. (2010), The Global Sea Level Observing System (GLOSS), paper presented at OceanObs'09, Eur. Space Agency, Venice, Italy, 21-25, Sep.

Nerem, R., and G. Mitchum (2002), Estimates of vertical crustal motion derived from differences of TOPEX/POSEIDON and tide gauge sea level measurements, Geophys. Res. Lett., 29(19), 1934, doi:10.1029/ 2002GL015037.

Peltier, W. R. (2004), Global glacial isostasy and the surface of the ice-age Earth: The ICE-5 G (VM2) model and GRACE, Annu. Rev. Earth Planet Sci., 32, 111-149, doi:10.1146/annurev.earth.32.082503.144359.

Pirazzoli, P. A. (1987), Recent sea-level changes and related engineering problems in the lagoon of Venice (Italy), Prog. Oceanogr., 18, 323-346, doi:10.1016/0079-6611(87)90038-3.

Pirazzoli, P. A., and A. Tomasin (2002), Recent evolution of surge-related events in the northern Adriatic area, J. Coastal Res., 18, 537-554.

Raucoules, D., et al. (2008), Ground deformation detection of the greater area of Thessaloniki (northern Greece) using radar interferometry techniques, Nat. Hazards Earth Syst. Sci., 8, 779-788, doi:10.5194/nhess-8779-2008.

Ray, R. D., B. D. Beckley, and F. G. Lemoine (2010), Vertical crustal motion derived from satellite altimetry and tide gauges, and comparisons with DORIS, Adv. Space Res., 45, 1510-1522, doi:10.1016/j.asr.2010. 02.020 .

Santamaría-Gómez, A., M.-N. Bouin, X. Collilieux, and G. Wöppelmann (2011), Correlated errors in GPS position time series: Implications for velocity estimates, J. Geophys. Res., 116, B01405, doi:10.1029/ 2010JB007701.

Spada, G., and P. Stocchi (2007), SELEN: A Fortran 90 program for solving the "sea level equation," Comput. Geosci., 33, 538-562, doi:10.1016 j.cageo.2006.08.006.

Stanley, D. J. (1990), Recent subsidence and northeast tilting of the Nile delta, Egypt, Mar. Geol., 94, 147-154, doi:10.1016/0025-3227(90) 90108-V.

Stiros, S. C. (2001), Subsidence of the Thessaloniki (northern Greece) coastal plain, 1960-1999, Eng. Geol. Amsterdam, 61, 243-256, doi:10.1016/S0013-7952(01)00027-8

Stiros, S. C., P. A. Pirazzoli, M. Fontugne, M. Arnold, and G. Vougioukalakis (2005), Late-Holocene coastal uplift in the Nisyros volcano (SE Aegean Sea): Evidence for a new phase of slow intrusive activity, Dev. Volcanol., 7, 217-225, doi:10.1016/S1871-644X(05)80041-5.

Street, J. O., R. J. Carroll, and D. Ruppert (1988), A note on computing robust regression estimates via iteratively reweighted least squares, $\mathrm{Am}$. Stat., 42, 152-154, doi:10.2307/2684491.

Trisirisatayawong, I., M. Naeije, W. Simons, and L. Fenoglio-Marc (2011), Sea level change in the Gulf of Thailand from GPS-corrected tide gauge data and multi-satellite altimetry, Global Planet. Change, 76, 137-151, doi:10.1016/j.gloplacha.2010.12.010.

Tsimplis, M. N. (1997), Tides and sea-level variability at the Strait of Euripus, Estuarine Coastal Shelf Sci., 44, 91-101, doi:10.1006/ecss.1996.0128.

Tsimplis, M. N., and N. E. Spencer (1997), Collection and analysis of monthly mean sea level data in the Mediterranean and Black Seas, J. Coastal Res., 13, 534-544.

Tsimplis, M. N., and T. F. Baker (2000), Sea level drop in the Mediterranean Sea: An indicator of deep water salinity and temperature changes? Geophys. Res. Lett., 27, 1731-1734, doi:10.1029/1999GL007004.

Tsimplis, M. N., A. G. P. Shaw, A. Pascual, M. Marcos, M. Pasaric, and L. Fenoglio-Marc (2008), Can we reconstruct the 20th century sea level variability in the Mediterranean Sea on the basis of recent altimetric measurements?, in Remote Sensing of the European Seas, edited by V. Barale 
and M. Gade, pp. 307-318, Springer, Dordrecht, Netherlands, doi:10.1007/ 978-1-4020-6772-3 23.

Tsimplis, M., G. Spada, M. Marcos, and N. Flemming (2011), Multi-decada sea level trends and land movements in the Mediterranean Sea with estimates of factors perturbing tide gauge data and cumulative uncertainties, Global Planet. Change, 76, 63-76, doi:10.1016/j.gloplacha.2010.12.002.

Volkov, D. L., G. Larnicol, and J. Dorandeu (2007), Improving the quality of satellite altimetry data over continental shelves, J. Geophys. Res., 112, C06020, doi:10.1029/2006JC003765.

Williams, S. D. P. (2008), CATS: GPS coordinate time series analysis software, GPS Solut., 12, 147-153, doi:10.1007/s10291-007-0086-4.

Woodworth, P. L. (2003), Some comments on the long sea level records from the northern Mediterranean, J. Coastal Res., 19, 212-217.
Woodworth, P. L., and R. Player (2003), The permanent service for mean sea level: An update to the 21st century, J. Coastal Res., 19, 287-295.

Wöppelmann, G., B. Martin Miguez, M.-N. Bouin, and Z. Altamimi (2007), Geocentric sea-level trend estimates from GPS analyses at relevant tide gauges world-wide, Global Planet. Change, 57, 396-406, doi:10.1016/ j.gloplacha.2007.02.002.

M. Marcos, IMEDEA, CSIC-UIB, Miquel Marquès 21, E-07190 Esporles, Spain

G. Wöppelmann, LIENSS, Université de la Rochelle-CNRS, 2 Rue Olympe de Gouge, F-17000 La Rochelle, France. (gwoppelm@univ-lr.fr.fr) 